\title{
The urgency of food system transformation is now irrefutable
}

\begin{abstract}
To the Editor - Poor diets are the main contributor to the global burden of disease, accounting for $20 \%$ of premature disease-mediated mortality worldwide ${ }^{1}$. Approximately 3 billion people cannot afford a healthy diet, and more than 3 billion people suffer one or more manifestations of poor nutrition ${ }^{2}$. Poor nutrition can lead to reduced earning potential and increased costs for healthcare, it locks individuals and families into inter-generational cycles of poverty and deprivation, and perpetuates inequality and disadvantage.
\end{abstract}

Even without projected global population growth - predicting a global population of 9.7 billion by $2050^{3}-$ it is likely that food systems are already operating beyond some planetary boundaries ${ }^{4-6}$. Agriculture and its associated land-use changes are the biggest contributors to climate change, accounting for roughly $21 \%$ of anthropomorphic greenhouse gas emissions between 2007 and 2016. Pressures placed on natural resources by food production have left $25 \%$ of the globe's cultivated land area degraded, while deforestation for agriculture and the intensification of agricultural landscapes are major contributors to biodiversity loss. . Threats posed by climate change - shifts in temperature and rainfall, and more frequent and damaging weather anomalies - directly and indirectly (for example, through pest and disease outbreaks) disrupt the production, processing, transport and marketing of food. Furthermore, the environmental damage caused by the current management of food systems amplifies disruption - extreme weather events precipitate forced migration, exacerbate tensions around the use of scarce freshwater or fish stocks, and can fuel political instability9.

It is against the background of these diverse policy challenges - and the COVID-19 pandemic, which has exposed the fragility of food systems - that the Global Panel on Agriculture and Food Systems for Nutrition has prepared a second Foresight report: Future Food Systems: For People, Our Planet, and Prosperity ${ }^{10}$. The nature and gravity of the challenges linking agriculture and food value chains to diets, health and planetary ecosystems can no longer be ignored - the case for fundamental transformation of food systems is now irrefutable.

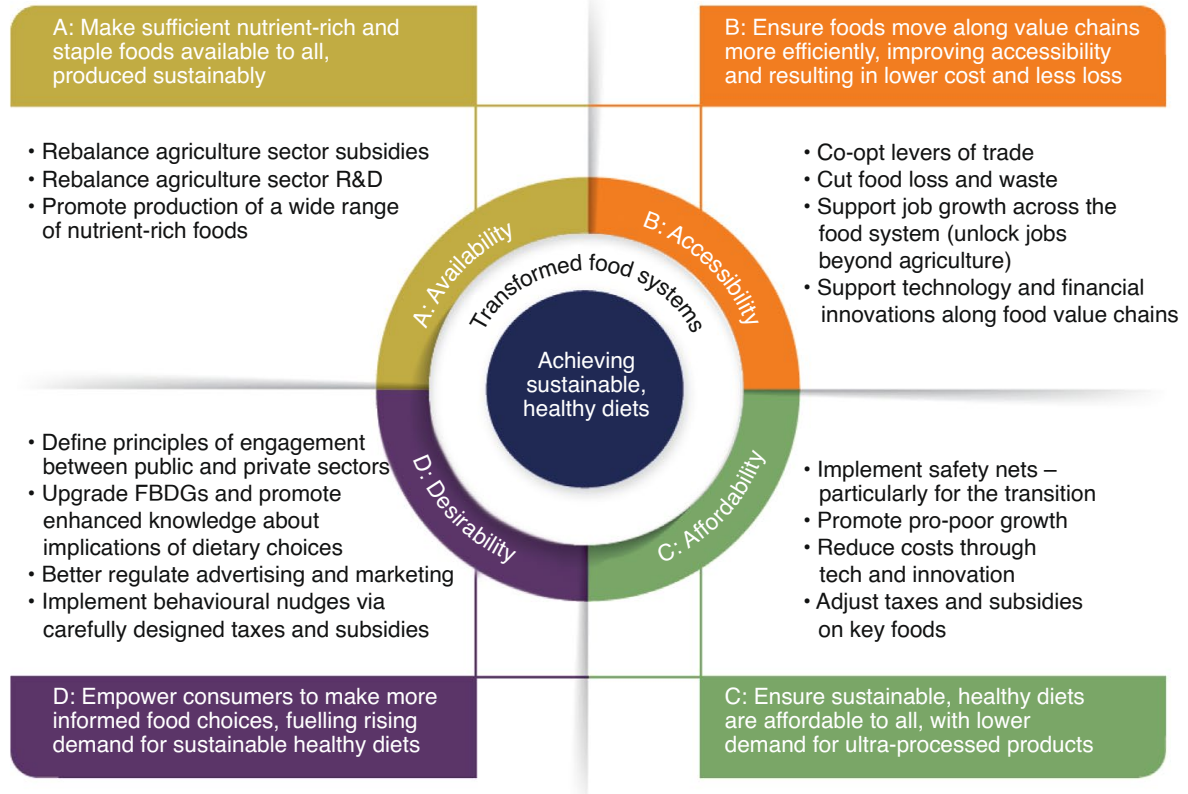

Fig. 1 | Priority policy actions to transition food systems towards sustainable, healthy diets. The foods that are essential for healthy diets must be produced sustainably and in sufficient quantity - today's systems fail in this regard, particularly with respect, for example, to fruit, vegetables and nuts (A). Food must be stored, transported, processed and marketed so that losses and waste are avoided, while also offering significant new opportunities for employment and income growth (B). The unaffordability of healthy diets for three billion people must be resolved, for example, with reform of agricultural subsidies (C). Citizens must be empowered to choose - including through improved policy-facing food-based dietary guidelines (FBDGs) - and access affordable diets that are healthy and sustainable (D). Credit: Reproduced with permission from ref. ${ }^{10}$, Global Panel on Agriculture and Food Systems for Nutrition.

Achieving transformation will require a major shift in mindsets - especially regarding possible futures versus the status quo, and roles and responsibilities of public sector actors versus businesses in shaping dietary demand. Food systems contribute to economic prosperity, human health, and planetary health, and getting all three right matters. They are interlinked, exerting considerable influence on each other. There is no single dietary pattern or food system that can or should be imposed globally, recognizing that foods are not just commodities but a key underpinning of local cultures, nutrition, livelihoods, and the shaping of landscapes. Every society must envisage potential new futures in which everyone eats healthily, based on food systems that are environmentally and economically sustainable as well as socially just. Local and national views on how such food systems might look in their own context should inform policy priorities aimed at achieving long-term transformation.

But shifts in mindsets alone do not feed people. Important, urgent steps must be taken without delay to support a carefully managed transition process. While food systems are dynamic and complex, a set of key policy actions can be pursued to address systemic weaknesses. The Foresight report proposes that such a set be applied in coherent ways across four key domains of all food systems, and highlights evidence-based examples of actions that represent first steps into the all-important transition (Fig. 1).

Food system reform is critical to many global agendas. Achieving the United Nations Sustainable Development Goals (SDGs), and meeting the aspirations of the Paris Agreement and the Convention on Biological Diversity, require significant food system changes. And yet, neither the Paris 
Agreement commitments nor the SDGs explicitly mention the promotion of healthy diets or the sustainability of food systems. The Paris Agreement commitments are approached largely sector by sector, and the SDGs are approached goal by goal. There is limited attention given to how actions in one sector and one policy agenda must be integrated with others. Concerted efforts that are better integrated between different goals or commitments, seen through a food systems lens, are essential to achieve the desired dietary patterns required to address equity, health, and planetary challenges.

There are many political barriers, economic constraints and policy hurdles to be faced. For example, the lack of coherence in areas of policy relating to food systems is a common feature of most governments $^{11,12}$. Governments have often struggled to make the difficult choices needed to achieve meaningful changes that influence diets. Bolder leadership is needed to enact the major reforms required. Furthermore, protecting and enhancing food consumption of the poor during the transition of food systems will be critical - these are the people who will be most vulnerable to fluctuations in supply and price ${ }^{13}$.

From the outset, decision makers need to focus on actions to improve food systems in ways that deliver multiple benefits simultaneously, not just more or better food but also jobs, income growth, innovation, and reduced negative externalities on the environment. There are examples of the potential for multiple-win changes, such as the restoration of China's Loess Plateau, a programme representing investments that offer simultaneous combined benefits for natural resources, poverty reduction and job creation ${ }^{14}$.

Food systems commonly operate across international borders, and their failures therefore have global implications. Governments and their development partners, including the UN, must work together urgently to build on existing mechanisms to support science and policy engagement with food systems transformation. International consensus, based on a strong evidence base, can help create the momentum for national action and provide an enabling environment for action within states and communities. To this end, the upcoming Food Systems Summit, UNFCCC COP26, UNCBD COP15 and the Nutrition for Growth Summit, are important opportunities, as food systems intimately influence each of their agendas.

With these summits in 2021, there is potential for meaningful change. Three priorities are clear: (1) inter-governmental and global institutional mechanisms are needed to provide credible and authoritative consensuses on scientific evidence - to support decisive and effective policies; (2) research efficiency and linkages need to be improved across science on climate, natural resources, food, health, and nutrition - to support multi-sectoral policies; and (3) robust synthesis and assessment processes are needed to strengthen the legitimacy of scientific advice through transparency that encompasses the perspectives of low- and middle-income countries. Confidence in science is needed to translate research into science-led policies, even though this will take time and is unlikely to be straightforward. This ambition exceeds the remit of any existing science advisory body for policy at the national or international level.

Looking further ahead, the transition process will require sustaining a long-term commitment, during which there will be many policy and economic trade-offs as well as political battles to be faced by policymakers. International cooperation will be crucial. The inter-connectedness of food markets and trade means that no one country alone can fully change their food system. National solutions thus require regional and global cooperation on goals that go far beyond today's SDGs, linking social wellbeing and planetary health.

Such cooperation is unlikely to emerge by itself and so those preparing for next year's summits must grasp opportunities now. The parameters for cooperation (including target-setting, improving the support and use of science to guide practice) and principles for engagement between public and private sectors should all be explored, defined, and costed in advance.
2021 is the time for agreement on the critical decisions that must be made - a new set of unfulfilled commitments must be avoided at all costs.

\section{Patrick Webb (D) 1,2凶, Tim G. Benton (D) 2,3, John Beddington², Derek Flynn², Niamh M. Kelly (D) ${ }^{2}$ and Sandy M. Thomas ${ }^{2}$ ${ }^{1}$ Friedman School of Nutrition Science and Policy, Tufts University, Boston, MA, USA. ${ }^{2}$ Global Panel on Agriculture and Food Systems for Nutrition, London, UK. ${ }^{3}$ Royal Institute of International Affairs, Chatham House, London, UK.

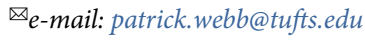

Published online: 28 September 2020 https://doi.org/10.1038/s43016-020-00161-0

References

1. Afshin, A. et al. Lancet 393, 1958-1972 (2019).

2. The State of Food Security and Nutrition in the World 2020: Transforming Food Systems for Affordable Healthy Diets (FAO, IFAD, UNICEF, WFP and WHO, 2020); https://doi.org/ 10.4060/ca9692en

3. World Population Prospects 2019: Highlights (UN, 2019).

4. Steffen, W. et al. Science 347, 1259855 (2015).

5. Sterner, T. et al. Nat. Sustain. 2, 14-21 (2019).

6. Gerten, D. et al. Nat. Sustain. 3, 200-208 (2020).

7. IPCC Climate Change and Land: an IPCC Special Report on Climate Change, Desertification, Land Degradation, Sustainable Land Management, Food Security, and Greenhouse Gas Fluxes in Terrestrial Ecosystems (eds Shukla, P. R. et al.) (IPCC, 2019).

8. Daskalova, G. N. et al. Science 368, 1341-1347 (2020).

9. States of Fragility 2018 (OECD, 2018).

10. Future Food Systems: For People, Our Planet, and Prosperity (Global Panel on Agriculture and Food Systems for Nutrition, 2020).

11. Cohen, M. J. Food Ethics 4, 175-187 (2019).

12. Thow, A. M. et al. Food Secur. 10, 1105-1130 (2018).

13. Green, R. et al. BMJ 346, $\mathrm{f} 3703$ (2013).

14. Tsunekawa, A. et al. (eds) Restoration and Development of the Degraded Loess Plateau, China (Springer, 2014).

\section{Acknowledgements}

The authors would like to acknowledge the following individuals who contributed to the work underlying this paper as members of the Global Panel's Foresight Lead Expert Group: J. Berdegué, Food and Agriculture Organization of the United Nations (FAO); J. Fanzo, Berman Institute of Bioethics at Johns Hopkins University; L. Haddad, Global Alliance for Improved Nutrition (GAIN); S. Myers, Harvard T. H. Chan School of Public Health, and the Planetary Health Alliance; M. Qaim, University of Goettingen; D. Resnick, International Food Policy Research Institute (IFPRI); M. Springmann, University of Oxford. The authors would also like to acknowledge the contribution of the Foresight project manager, S. Brown.

Competing interests

The authors declare no competing interests. 